\title{
PREPARATION AND CHARACTERIZATION OF
}

\section{MODIFIED NATURAL POLYMER}

\author{
Meligi, G. A. ${ }^{(1)}$; Rezoka, Sh. ${ }^{(2)}$; Mahmoud, Ghada, A. ${ }^{(3)}$ \\ and Khalil, M. M. H. ${ }^{(1)}$
}

1) Faculty of Science, Ain Shams University 2) Holding Company for Water and Wastewater 3) National Center for Radiation Research and Technology, Atomic Energy Authority.

\begin{abstract}
This paper discusses the removal of ammonium ions $\left(\mathbf{N H}_{4}\right)^{+}$from raw water using a hydrogel as an adsorbent. The raw water has been obtained from Fesha water treatment plant which is a traditional treatment plant located in Behera. For this purpose, kappa carrageenan/acrylic acid hydrogel (KC/AAc) were prepared via free radical polymerization using gamma irradiation. The effect of irradiation dose and (AAc) concentration on gel content was studied. The formed hydrogel was characterized by FTIR and SEM. The swelling behavior was determined as a function of irradiation dose, and AAc content. The developed hydrogel was used for the removal of $\left(\mathbf{N H}_{4}\right)^{+}$ions. The effects of various operating parameters such as initial $\mathrm{pH}$, contact time, and adsorbent dose on the removal of $\left(\mathbf{N H}_{4}\right)^{+}$ions have been investigated. It was found that the optimum $\mathrm{pH}$ value is 5 and the perfect adsorbent dose is $15 \mathrm{gm} / \mathrm{L}$. A fast adsorption rate was observed the equilibrium was reached within $50 \mathrm{~min}$ and the maximum removal percent was $(52.7 \%)$.
\end{abstract}

Keyword: kappa carrageenan; ammonium ion removal; hydrogel;Irradiation; adsorption

\section{INTRODUCTION}

Raw Water in Nile branch Rosetta is contaminated by different domestic and industrial water. It contains various inorganic, organic and biological contaminants that are of high environmental impact and significance. These 
contaminants can create health hazards if discharged into streams or oceans without proper care and treatment. They represent a load on the drinkingwater treatment plant, especially in winter blockage period (WBP). Every day there are 3.5 million $\mathrm{m}^{3}$ of waste and industrial water are discharge in The Nile branch Rosetta which is mixed with 20 million $\mathrm{m}^{3}$ of raw water but in the winter blockage period (WBP) about 3.5 million $\mathrm{m}^{3}$ of waste and industrial water are discharge in the Nile branch Rosetta which is mixed with 5 million $\mathrm{m}^{3}$ only of raw water.

Disinfectant by-products (DBPs) are probable carcinogens and short-term exposure can lead to dizziness, headaches, as well as problems associated with the central nervous system. Recent studies have also linked DBPs to increased incidence of miscarriage, rectal and bladder cancer, and neural tube birth defects. Ammonia in surface water supplies often is a result of runoff in agricultural areas where fertilizer applied to the ground. Another way that high level of ammonia in water appears is from aquifers in animal feed lots. Ammonia is oxidized to nitrate by bacterial action. In drinking water the maximum ammonia concentration of $0.5 \mathrm{mg} / \mathrm{L}$ is recommended by the World Health Organization (WHO) to avoid changes of taste and odor of water. The presence of $\left(\mathbf{N H}_{4}\right)^{+}$ions in water lead to dissolved oxygen depletion, fish toxicity in receiving water leading thus to a number of health problems involving living species such as humans and animals (De-Bashan et al, 2004). In order to remove $\left(\mathbf{N H}_{4}\right)^{+}$, several technologies have been tested, namely biological treatment (Welander et al, 1998), Chemical precipitation (Uludag-Demirer et al, 2005), Supercritical water oxidation( such as 
chlorination ) (Segond $\boldsymbol{e t}$ al,2002), ion exchange and adsorption (Vassileva $\boldsymbol{e t}$ $\boldsymbol{a l}$, 2009). Among these methods, adsorption technology has received much attention and is considered to be a robust and effective technique used in water and wastewater treatments due to its low cost of application, low energy input and easy operation.

Carrageenan is a natural carbohydrate (polysaccharide) obtained from edible red seaweeds. Carrageenan $(\mathrm{KC})$ is widely used in the food industry, for their gelling, thickening, and stabilizing properties. It is used in experimental medicine, pharmaceutical formulations, cosmetics, and industrial applications.

There are three main varieties of carrageenan, which differ in their degree of sulfation. Kappa-carrageenan has one sulfate per disaccharide. Iotacarrageenan has two sulfates per disaccharide. Lambda carrageenan has three sulfates per di-saccharide. Herein, we have demonstrated a simple, economical and environmentally method for removal ammonium ions $\left(\mathbf{N H}_{4}\right)^{+}$ from drinking water planet. Water purification by hydrogel based on (acrylic acid) grafted onto kappa carrageenan. The influences of uptake capacity of hydrogel according to the different contact times and initial concentrations were investigated.

\section{AIM OF THE WORK}

\section{The aim of study will be focused on the following targets:}

1- Radiation grafting of some synthetic monomers such as acrylic acid on some natural polymers such as carrageenan.

2- The prepared grafted copolymer will be characterized by investing their characteristic properties, such as structural characteristics FTIR and SEM. 
3- The ability of prepared polymeric material to remove ammonium ions $\left(\mathbf{N H}_{4}{ }^{+}\right)$from drinking water planet.

4- The factors may affect wastewater treatment will be optimized such as $\mathrm{pH}$, dosage of adsorbent and contact time.

\section{MATERIALS AND METHODS}

\section{Materials:}

- Raw water used was collected from Fesha water treatment plant (FWTP). This located on Nile branch Rosetta.

- All chemicals and reagents used were of analytical grade and of analyticalreagent purity and Nano-pure water was used throughout the whole work.

\section{Methods:}

Raw water was obtained from (FWTP) In 20 liter bottle made of polyethylene, the bottle was washed once with the sample. Then the bottles were filled with the sample and closed.

The examined sample from the selected locations was transferred to the laboratory of (FWTP) and portion of sample was transferred to reference laboratory for wastewater in Abu Rawash treatment plant (ARTP). The characteristics of the raw water were variable. The jar test has been applied to evaluate the Jar testing experiments were carried out using samples which taken from the influent from (FWTP) .That includes screening, coagulation, flocculation, sedimentation, filtration and disinfection. 


\section{Preparation of KC/AAc hydrogels:}

Carrageenan powder $(1 \mathrm{~g})$ was dissolved in $(100 \mathrm{ml})$ distilled water contained $19.08 \mathrm{ml}(\mathrm{AAc})$, which placed on water bath at $60 \mathrm{C}^{\mathrm{o}}$ for 3 hours to form homogeneous mixture. The viscous solution was transferred into the glass tube to be irradiated by (Co 60) gamma source at room temperature and different radiation dose $(10,15,20,25$ and $30 \mathrm{kGy})$. After copolymerization, the vials broken, the formed polymeric cylinders were removed and cut into small discs. All samples were washed in excess hot water to remove the unreacted compounds, then air dried at room temperature.

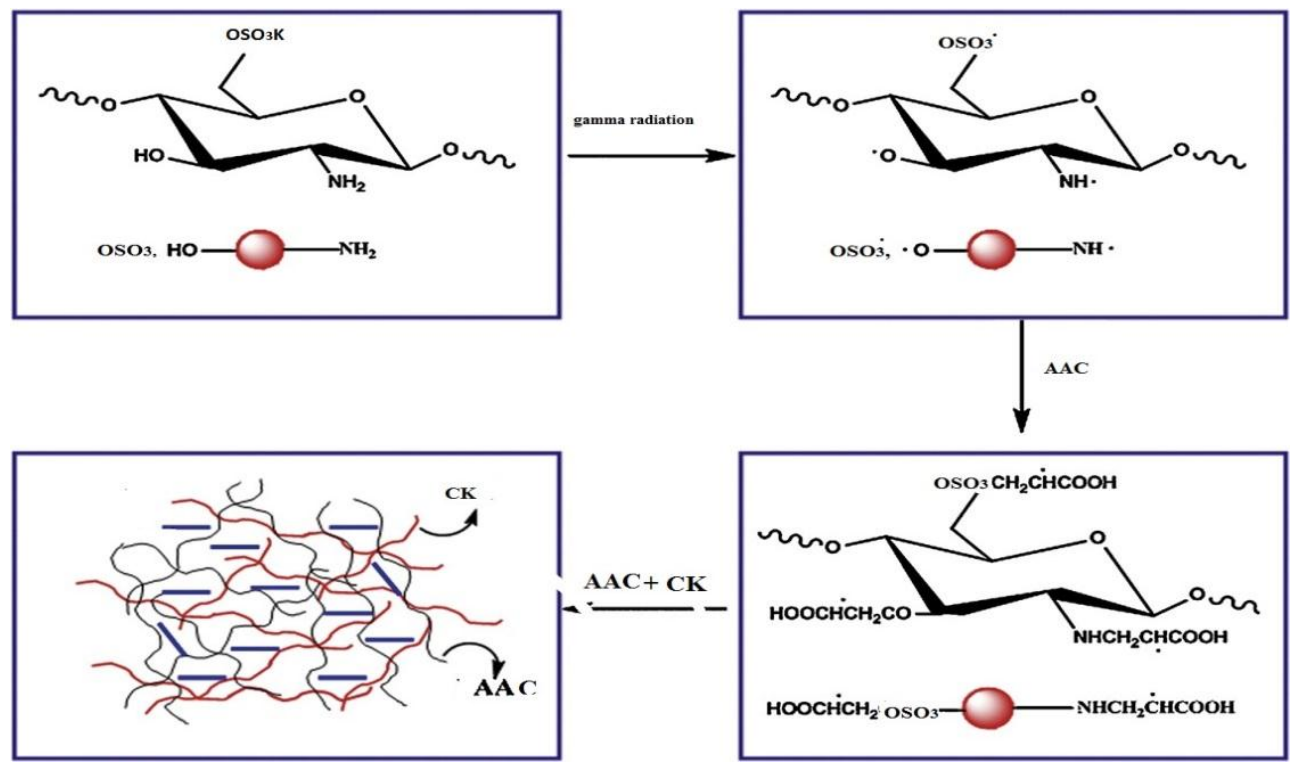

Schematic preparation of (CK/AAC) hydrogel.

Gel content measurements: The irradiated hydrogel samples were air-dried to a constant weight. The dried samples were soaked in distilled water for $24 \mathrm{hr}$ at $60 \mathrm{C}^{\circ}$ at water bath to determine the insoluble parts of the hydrogel. Then, they were taken out and washed with hot water to remove the soluble 
part, dried to a constant weight. The gel content was calculated gravimetrically using the following formula:

$$
\text { Gel content }(\%)=\frac{w_{\mathrm{d}}}{w_{0}} \times 100
$$

Where $\mathrm{W}_{\mathrm{d}}$ and $\mathrm{W}_{0}$ are the dried sample weights after and before extraction, respectively.

Swelling measurements: The swelling degree was determined on the basis of equilibrium solvent-swelling measurements. The samples were submerged in the solvent (distilled water or puffer solution) and till the swelling equilibrium, the gels were removed and the excess water on the surface was removed by blotting quickly with filter paper and weighed. The swelling percent was calculated as follows:

$$
\text { Swellingpercent }=\frac{W s-W d}{W d} \times 100
$$

Where $\mathrm{W}_{\mathrm{S}}$ and $\mathrm{W}_{\mathrm{d}}$ are the weights of the swollen and the dried hydrogel, respectively.

\section{RESULT AND DISCUSSION}

Synthesis of hydrogels using gamma radiation: This study the hydrogels based on Kappa-carrageenan (KC) copolymerization with (AAc) with gamma irradiation to form (KC/AAc) hydrgel. Gamma radiation there is no need to add chemical initiators or crosslinking agents, which are mostly toxic materials (Rosiak and Ulansk 1999).Gamma irradiation on polysaccharides leads to the random formation of free radicals on polymer chains. These free radicals are responsible for such reactions as grafting and intermolecular crosslinking (Wach et al, 2003). Gel content measurement is an effective 48 
method for evaluating the degree of crosslinking of the polymeric hydrogel. Gel content is defined as the amount of insoluble polymer in any solvent. The gel content is affected by several factors such as radiation dose and monomer concentration.

Effect of gamma irradiation time and (AAc) dose on the gel percent: The effect of gamma irradiation dose on the gel percent of (KC/AAc) hydrogel at various (AAc) concentrations was investigated and shown in Figure (1). As shown in Figure (1) the gel percent of the (KC/AAc) hydrogel increased with increasing the irradiation dose up to $25 \mathrm{kGy}$ and a decrease was observed above this value (Demitri et al, 2008). The maximum gel percent was observed at radiation dose $25 \mathrm{kGy}$. 
J. Environ. Sci.

Institute of Environmental Studies and Research - Ain Shams University

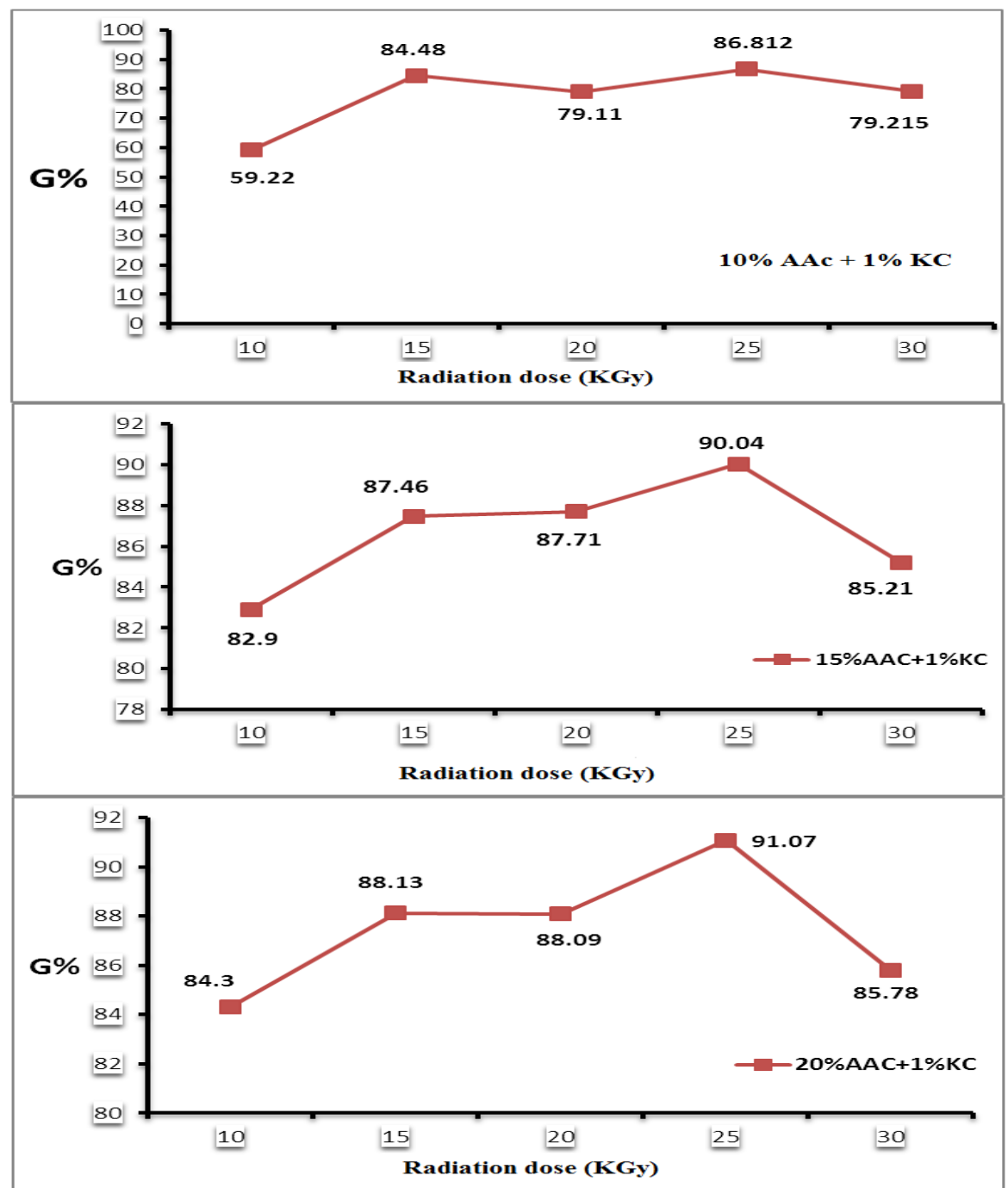

Figure (1): Effect of gamma radiation dose on the gel percent of (KC/AAc) hydrogel at various (AAc) concentrations and $(1 \%$ KC) concentration. 
The initial monomer concentration used in the gel preparation highly impressed the network structure and the gel properties. The properties of hydrogels are governed by the monomer content in the reaction mixtures. The effect of (AAc) content on the gel percent of (KC/AAc) hydrogel was shown in Figure (1). The gelation percent of (KC/AAc) hydrogel varies from $(86.8 \%$ to $91.0 \%$ ) for the increase in the concentration of (AAc) in the feed solution from (10\% to $20 \%)$ of the total monomer/polymer concentration at irradiation dose $25 \mathrm{kGy}$. When aqueous solution of (KC/AAc) was exposed to gamma rays, free radicals are generated which lead to formation of crosslinking copolymerization of the monomer-polymer mixture. As the monomer concentration is increased, effective density of crosslinks also increased resulting in a significant improvement in the degree of gelation. Meanwhile, the increase in the gelation degree as a result of the increase in the reactants concentration could be referred to increase the viscosity of reaction medium as well as the increase in the number of the reactive vinyl groups (Qudah $\boldsymbol{e t}$ $\boldsymbol{a l}$, 2013) The gelation percent of (KC/AAc) hydrogel varies from 86.8 to 91.0 $\%$ for the increase in the concentration of (AAc) in the feed solution from (10\% to $20 \%)$ of the total monomer/polymer concentration at irradiation dose (25 kGy). (PAAc) is well known as a crosslinked polymer by radiation. Consequently, as the polyacrylic acid increases in the graft-copolymer, the gel content increases. This may be explained on the formation of a complex by the temporary physical cross-linking hydrogen bonding between the (KC) and (AAc) pendant groups. 
Effect of $(\mathrm{KC})$ content on the gel percent of (KC/AAc) hydrogel: The effect of KC content on the gel percent of (KC/AAc) hydrogel using (10\% $\mathrm{AAc})$ and different concentration of $(\mathrm{KC})$ was investigated and shown in Figure (2).It can be seen that as the radiation dose increased the gel percent of the hydrogel decreased. Since (KC) is a radiation degradable polymer, (KC) molecule degrades to low molecular weight that causes the reduction of the gel percent of (KC/AAc) hydrogel. It can be also observed that at the same irradiation dose as the $(\mathrm{KC})$ content is increased the gel percent of the hydrogel is decreased. This means that the gel percent is inversely proportional to the $(\mathrm{KC})$ content in the hydrogel. This observation may be based on the viscosity of polymer, as the (KC) concentration increased the viscosity also increased as well as a small number of monomer radicals can diffuse onto the $(\mathrm{KC})$ backbone and the crosslink intensity decreased resulted in a decrease in the gel percent. 


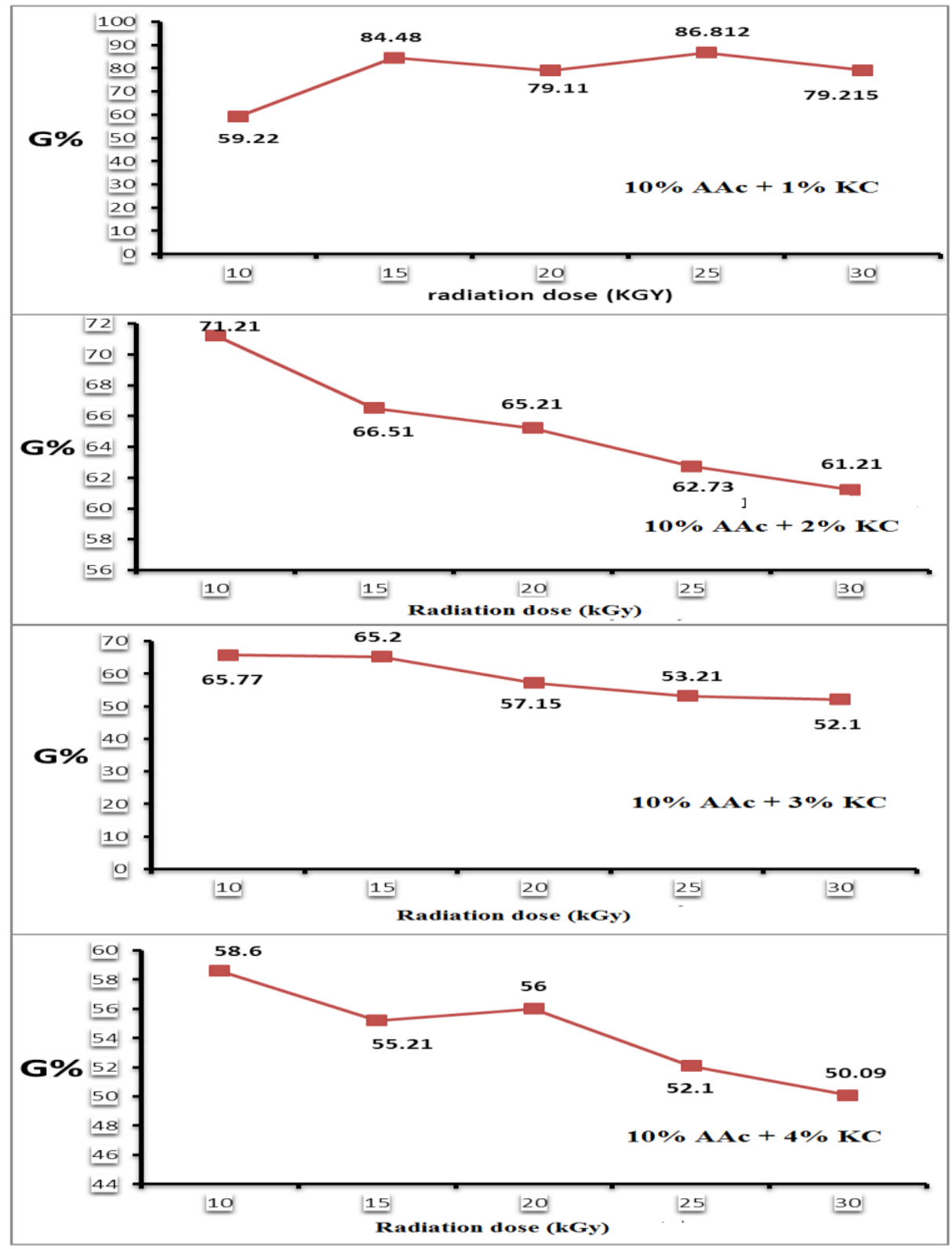

Figure (2): Effect of gamma radiation dose on the gel percent of (KC/AAc) Hydrogel at various $(\mathrm{KC})$ concentrations. 
Swelling behavior: The swelling property of hydrogel is an important factor concerned with its adsorption. When a hydrogel is brought into contact with water the water diffuses into the network, resulting in the expansion of the hydrogel. The swelling is a result of a balance between two forces the first is osmotic force and the second is dispersing force. Osmotic force pushes water into the polymer network whereas dispersing force exerted by the polymer chains resist it. The equilibrium of swelling occurs when the values of the osmotic force and of the dispersing become equal. The percentage of swelling of the hydrogel is mainly governed by the polarity of the formulations which is dependent on the nature of the polymers and the reaction conditions such as swelling time.

Effect of gamma radiation on the swelling percent: Radiation dose is one of the important parameters that affect the swelling behaviors of hydrogels. Figure (3) show the effect of radiation dose on the swelling percent of (KC/AAc) hydrogel at radiation doses ranged from (10 to $30 \mathrm{kGy}$ ). As shown in the Figure (3) as the radiation dose is increased the swelling percent decreased and the highest swelling percent was obtained at (10 kGy) for all investigated samples. This result matched with the result that obtained in other studied (Putra et al, 2009). The decrease in the swelling ability with increasing irradiation dose attributed to the higher degree of crosslinking under the high irradiation dose. The increase in the crosslink density enhances the dispersing force, excessive crosslink restricts the mobility of the polymer chains and a decrease in the swelling percent was observed. 
Meligi, et al
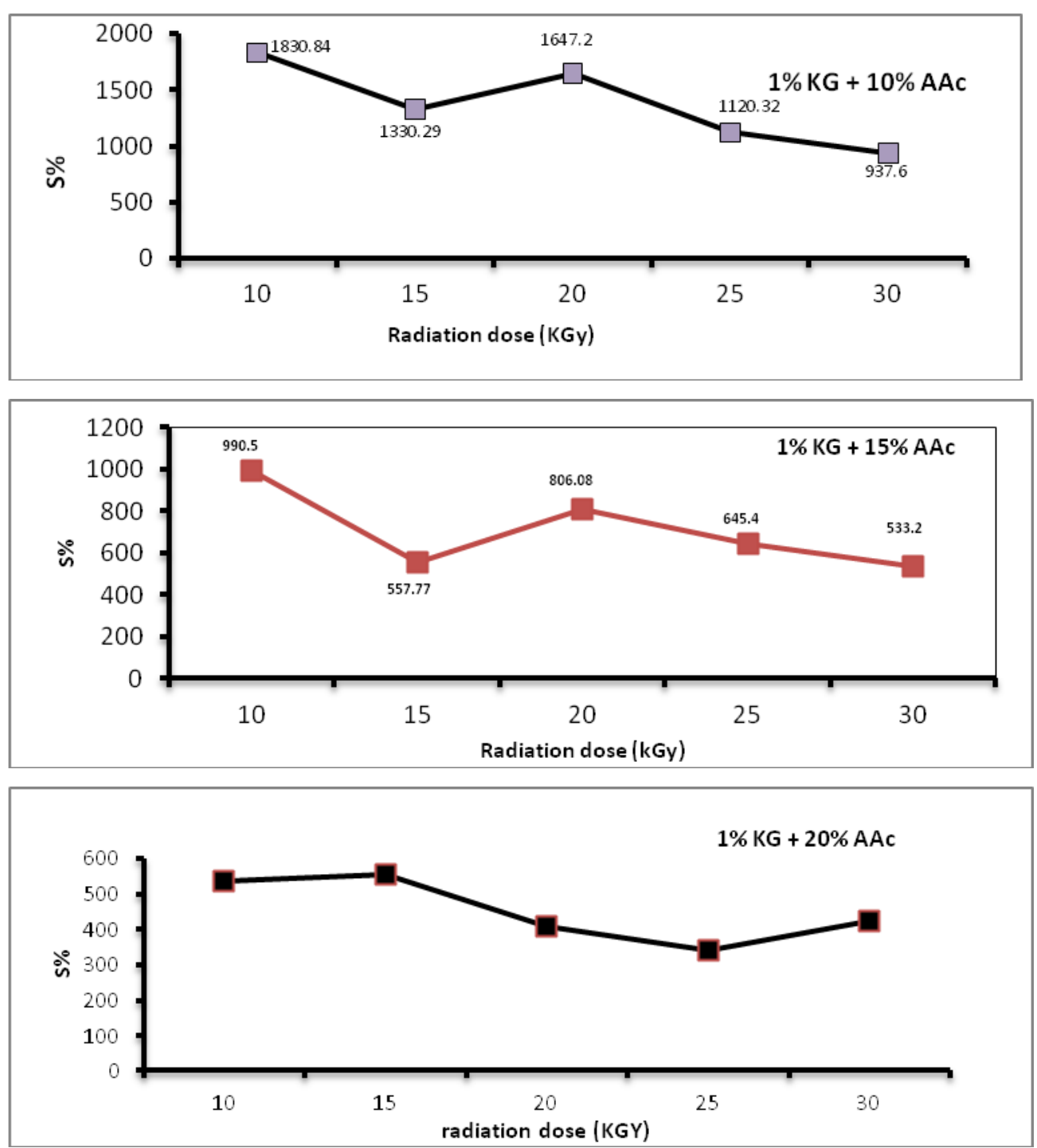

Figure (3): Effect of gamma radiation dose on the swelling percent of (KC/AAc) hydrogel at various (AAc) concentrations and a swelling time $24 \mathrm{~h}$. 
Effect of (AAc) content on the swelling percent of (KC/AAc) hydrogel: the effect of (AAc) content on the swelling percent of (KC/AAc) hydrogel was studied and shown in Figure (4). As seen in Figure as the monomer content was increased the swelling percent of (KC/AAc) hydrogel decreased. This result due to increase the cross-link density with increasing the (AAc) concentration of the feed solution thus a decrease in the pore size which has decreased the amounts of water uptake by the hydrogels

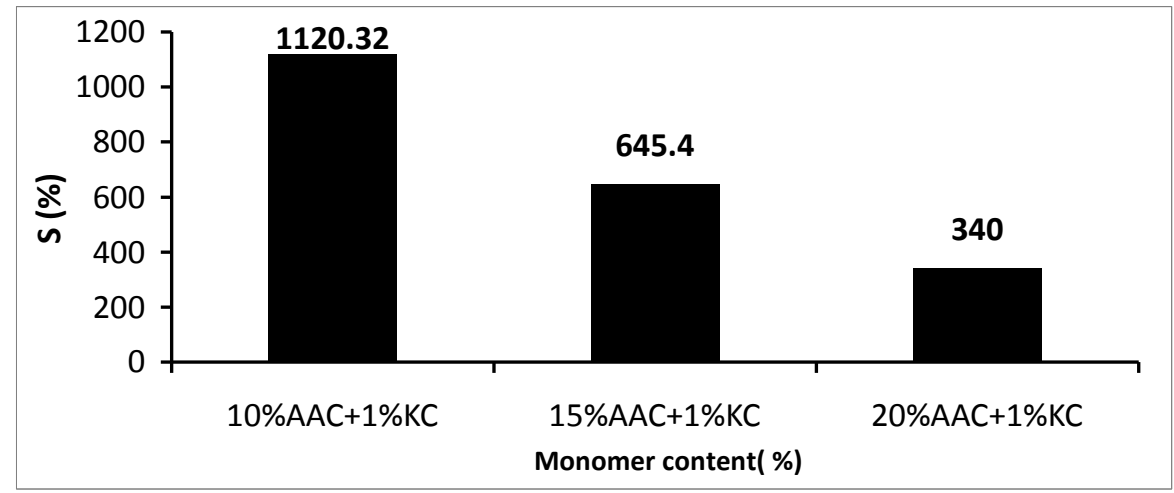

Figure (4): Effect of monomer content on the swelling percent of (KC/AAc) hydrogel at contact time $24 \mathrm{~h}$ at radiation dose $25 \mathrm{kGy}$.

Characterization and some selected properties of the prepared hydrogels:

Fourier Transfer Infrared Spectra (FTIR): The functional groups of the synthesized hydrogels were characterized by FTIR. Figure (5) shows the FTIR spectra of (KC, KC/AAc) hydrogel, where the percent of transmittance was plotted as a function of the wavenumber $\left(\mathrm{cm}^{-1}\right)$. 
For $\kappa$-carrageenan [Figure $(5 \mathrm{~A})$ ], it can be observed that a broad band at $\left(3415 \mathrm{~cm}^{-1}\right)$ indicating the stretching vibration of $(-\mathrm{OH})$ group. The band found at $\left(1646 \mathrm{~cm}^{-1}\right)$ related to the polymer bound water and the asymmetric stretching band of $(\mathrm{O}=\mathrm{S}=\mathrm{O})$ appeared at $\left(1377 \mathrm{~cm}^{-1}-1160 \mathrm{~cm}^{-1}\right)$. The band appeared at $\left(1070 \mathrm{~cm}^{-1}\right)$ corresponding to the glycosidic bond in carrageenan and the band observed at $\left(928 \mathrm{~cm}^{-1}\right)$ presented of the ether group in the anhydro-galactose. The bands at $\left(847 \mathrm{~cm}^{-1}\right.$ and $\left.736 \mathrm{~cm}^{-1}\right)$ due to galactose-4sulfate that are the characteristic peaks of $\kappa$-carrageenan (Wan et al, 2014).

For (KC/AAc) hydrogel, Figure $(5 \mathrm{~B})$, the additional bands of (AAc) appeared but some bands overleaped with the bands of (KC). It was observed that the band of the $(\mathrm{OH})$ shifted from $\left(3415 \mathrm{~cm}^{-1}\right)$ to $\left(2908 \mathrm{~cm}^{-1}\right)$ due to the formation of hydrogen bonds. This suggests that the polymeric network is arranged in such a way that the possibility of hydrogen bonding is diminished.

The band at $\left(1740 \mathrm{~cm}^{-1}\right)$ is attributed to the stretching vibration of ($\mathrm{C}=\mathrm{O})$ of (AAc) group. The broad and intense bands centered at $\left(1240 \mathrm{~cm}^{-1}\right)$ and $\left(1419 \mathrm{~cm}^{-1}\right)$ are attributed to $(\mathrm{C}-\mathrm{O})$ stretching and $(\mathrm{C}-\mathrm{O}-\mathrm{H})$ bending vibrations. The presence of these bands confirmed the formation of (KC/AAc) cross-linked hydrogel. 
J. Environ. Sci.

Institute of Environmental Studies and Research - Ain Shams University

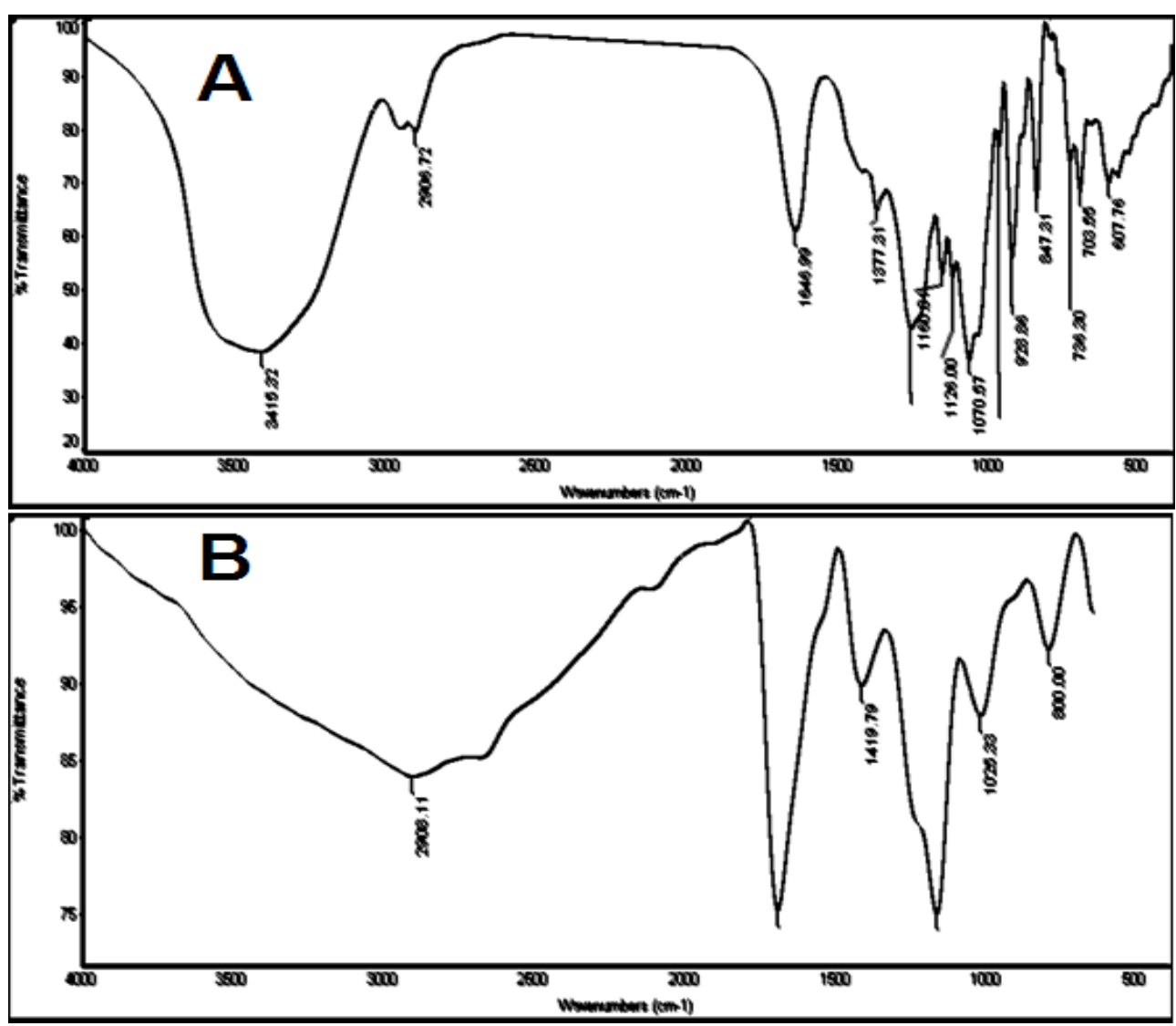

Figure (5): FTIR spectra of KC (A), KC/AAc (B) hydrogels.

Scanning Electron Microscope (SEM): (SEM) has been a primary tool for characterizing the surface morphology and fundamental physical properties of an adsorbent surface. It can be used to determine the particle shape, porosity and appropriate size distribution of an adsorbent. Figure (6) shows the surface morphology of $(\mathrm{KC})$ and $(\mathrm{AAc} / \mathrm{KC})$ hydrogel. As shown in Figure $(6 \mathrm{~A})$ the $(\mathrm{KC})$ as a Blank demonstrates a coarse surface with many small pores. Figure $(6 \mathrm{~B})$ shows the surface morphological structure of $(\mathrm{AAc} / \mathrm{KC})$ 
hydrogel which appears as coarse surface with spots and some porous structure. The reason is that there are numerous carboxylate anions in the hydrogels surfaces and inner structures. The electrostatic repulsions among the carboxylate anions can result in the expansion of the hydrogels network and increasing the pores size.

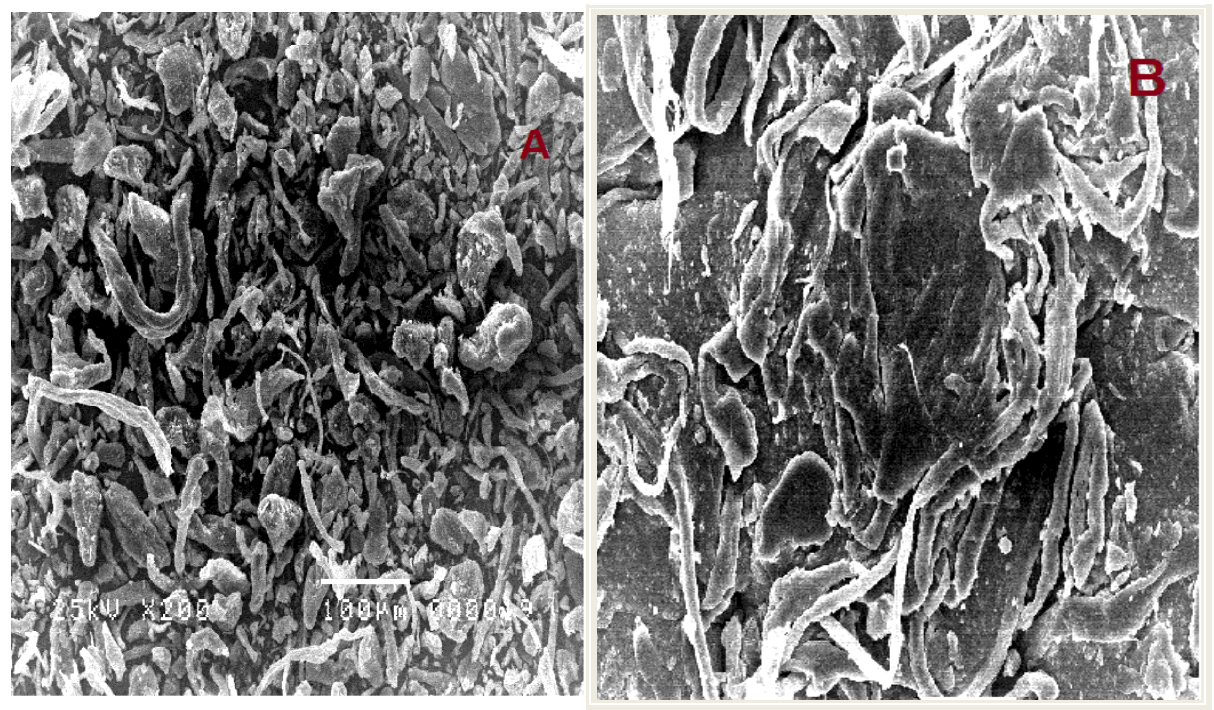

Figure (6): SEM of carrageenan (A), KC/AAC (B) hydrogel

\section{CONCOLUSION}

In this investigation, (KC/AAc) hydrogels were prepared by gamma irradiation and used for removal of ammonium ions from raw water. The most important conclusions of this investigation are the following:

- The gel content increased with increasing the (AAc) content in the hydrogel and the maximum gel percent was obtained at radiation dose of $25 \mathrm{kGy}$.

- The swelling percent decreased as the radiation dose and (AAc) concentration was increased. 
J. Environ. Sci.

Institute of Environmental Studies and Research - Ain Shams University

\section{REFRENCES}

Asano, T.(1987): Wastewater reclamation and reuse. Journal Water Pollution Control Federation,112(2), 429-431.

Chakraborty, S, Chowdhury, S, and Saha, P. D. (2011): Adsorption of crystal violet from aqueous solution onto $\mathrm{NaOH}$-modified rice husk. Carbohydrate Polymers, 86(4), 1533-1541.

De-Bashan, L. E., and Bashan, Y. (2004): Recent advances in removing phosphorus from wastewater and its future use as fertilizer (1997-2003). Water Research, 38(19), 4222-4246.

Demitri, C, Del Sole, R., Scalera, F., Sannino, A., Vasapollo, G., Maffezzoli, A. and Nicolais, L.(2008): Novel superabsorbent cellulose-based hydrogels crosslinked with citric acid. Journal of Applied Polymer Science, 110(4), 2453-2460.

Guo, L. (2007): Doing battle with the green monster of Taihu Lake. Science, 317(5842), 1166.

Hashem A, Abdel-Halim E. S, \&Sokker H. H. (2007): Bi-functional starch composites prepared by $\mathrm{\gamma}$-irradiation for removal of anionic and cationic dyes from aqueous solutions. Poly.Plas. Tech. Eng; 46, $1-77$.

Mohan, D., Singh, K. P., and Singh, V. K. (2006): Trivalent chromium removal from wastewater using low cost activated carbon derived from agricultural waste material and activated carbon fabric cloth. Journal of Hazardous Materials, 135(1), 280-295.

Onyango, M. S., Kuchar, D., Kubota, M., and Matsuda, H. (2007): Adsorptive removal of phosphate ions from aqueous solution using synthetic zeolite.Industrial\& Engineering Chemistry Research, 46(3), 894-900.

Putra, E. K., Pranowo, R., Sunarso, J., Indraswati, N., \&Ismadji, S. (2009): Performance of activated carbon and bentonite for adsorption of amoxicillin from wastewater: Mechanisms, isotherms and kinetics. Water Research, 43(9), 2419-2430. 
Qudah Y.H, Raafat A.I and El-Hag A.A.(2013): Removal of Some Heavy Metals from their Aqueous Solutions using 2- Acrylamido -2Methyl-1-Propane Sulfonic Acid/Polyvinyl Alcohol Copolymer Hydrogels Prepared by Gamma Irradiation, Arab. Nuc. Sci. Appl ; 46, 80-91

Rosiak, J. M., \&Ulań ski, P. (1999):.Synthesis of hydrogels by irradiation of polymers in aqueous solution.Radiation Physics and Chemistry, 55(2), 139-151.

Salleh, M. A. M., Mahmoud, D. K., Karim, W. A. W. A., \& Idris, A. (2011): Cationic and anionic dye adsorption by agricultural solid wastes: A comprehensive review. Desalination, 280(1), 1-13.

Segond, N., Matsumura, Y., and Yamamoto, K. (2002): Determination of ammonia oxidation rate in sub-and supercritical water. Industrial \& Engineering Chemistry Research, 41(24), 6020-6027.

Uludag-Demirer, S., Demirer, G. N., \& Chen, S. (2005): Ammonia removal from anaerobically digested dairy manure by struvite precipitation. Process Biochemistry, 40(12), 3667-3674.

Vassileva, P., Tzvetkova, P., and Nickolov, R. (2009): Removal of ammonium ions from aqueous solutions with coal-based activated carbons modified by oxidation. Fuel, 88(2), 387-390.

Wach R.A, Mitomo H, Nagasawa N and Yoshii F. (2003): Radiation crosslinking of carboxymethylcellulose of various degree of substitution at high concentration in aqueous solutions of natural pH, Radiat. Phys. Chem.; 68, 771-779

Wan Ahmad Kamil Mahmood, Mohammad Mizanur Rahman Khan and Teow Cheng Yee1, (2014): Effects of Reaction Temperature on the Synthesis and Thermal Properties of Carrageenan Ester, Journal of Physical Science, 25(1), 123-138.

Welander, U., Henrysson, T., and Welander, T. (1998): Biological nitrogen removal from municipal landfill leachate in a pilot scale suspended carrier biofilm process. Water Research, 32(5), 15641570 . 
J. Environ. Sci.

Institute of Environmental Studies and Research - Ain Shams University

Zaghouane-Boudiaf, H., Boutahala, M., and Arab, L. (2012): Removal of methyl orange from aqueous solution by uncalcined and calcinedMgNiAl layered double hydroxides (LDHs). Chemical Engineering Journal, 187, 142-149. 


\section{تحظير وتوعيفن بوليمر هطعه هالإشعاج الجاهيه هيه الكار بينا}

[r]

جمال عبد العزيز مليجي(')- شلبي رزوقة(†)- غادة عادل محمود(")

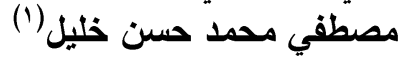

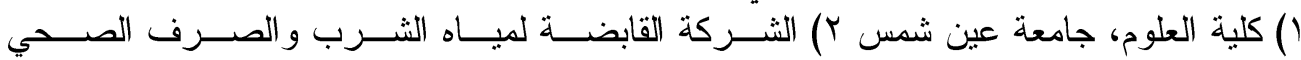
r) المركز القومي لبحوث وتكة وتكنولوجيا الإشعا، هيئة الطاقة الذرية

\section{المستخلص}

يهذف هذا البحث الي دراسة إزالة أيونات الأمونيوم +(NH4) من الماء الخئ الخام بواسطة

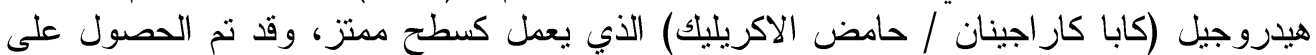

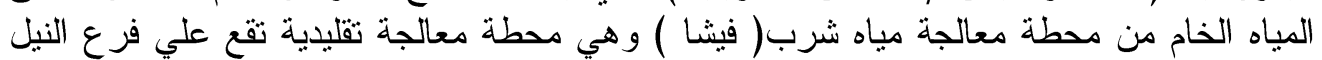
رشيد بمحافظة البحيرة . تم إعداد هيدروجيل (كابا كار اجينان / حامض الاكريليك) (KC / AAC)

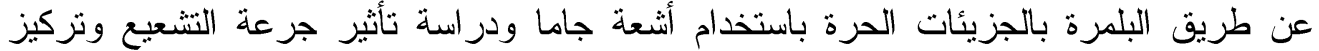

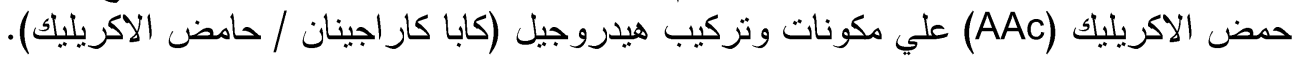

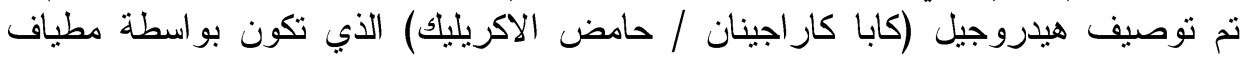

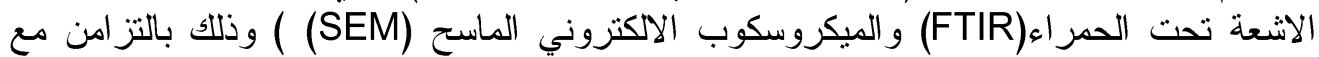

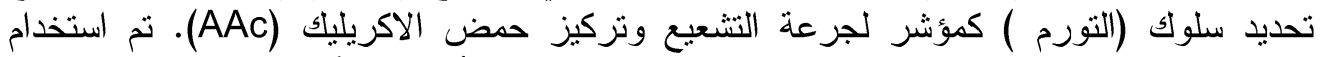

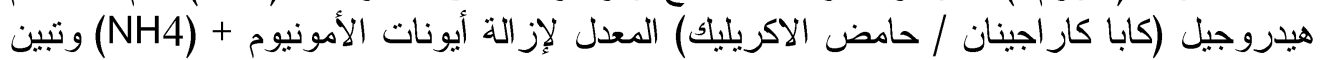

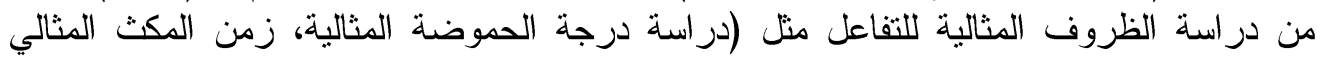

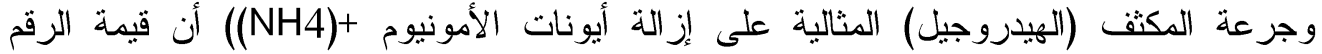

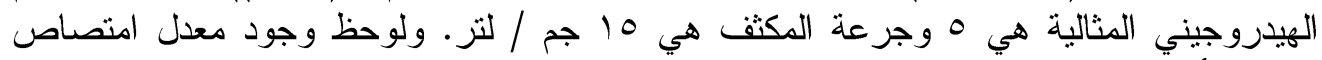

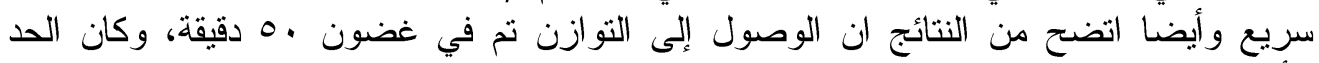

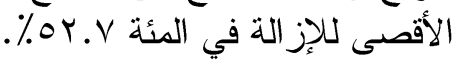
الكلمات: كارجينا, حمض الاكريليك, بوليمر ، أيون الأمونيوم, هيدروجيل, إثعاع, الإمتزاز. 